\title{
Antioxidant potential and optimization of production of extracellular polysaccharide by Acinetobacter indicus M6
}

Ch. Ravi Teja', Abraham P. Karlapudi², Neeraja Vallur ${ }^{3}$, K. Mamatha' ${ }^{1}$ D. John Babu², T. C. Venkateswarulu² and Vidya Prabhakar Kodali ${ }^{*}$ (D)

\begin{abstract}
Background: Extracellular polysaccharides (ECPs) produced by biofilm-producing marine bacterium have great applications in biotechnology, pharmaceutical, food engineering, bioremediation, and bio-hydrometallurgy industries. The ECP-producing strain was identified as Acinetobacter indicus M6 species by 165 rDNA analysis. The polymer produced by the isolate was quantified and purified and chemically analyzed, and antioxidant activities have been studied. The face-centered central composite design (FCCCD) was used to design the model.

Results: The results have clearly shown that the ECP was found to be endowed with significant antioxidative activities. The ECP showed $59 \%$ of hydroxyl radical scavenging activity at a concentration of $500 \mu \mathrm{g} / \mathrm{mL}$, superoxide radical scavenging activity (72.4\%) at a concentration of $300 \mu \mathrm{g} / \mathrm{mL}$, and DPPH' radical scavenging activity (72.2\%) at a concentration of $500 \mathrm{\mu g} / \mathrm{mL}$, respectively. Further, HPLC and GC-MS results showed that the isolated ECP was a heteropolymer composed of glucose as a major monomer, and mannose and glucosamine were minor monomers. Furthermore, the production of ECP by Acinetobacter indicus M6 was increased through optimization of nutritional variables, namely, glucose, yeast extract, and $\mathrm{MgSO}_{4}$ by "Response Surface Methodology". Moreover the production of ECP reached to $2.21 \mathrm{~g} / \mathrm{L}$ after the optimization of nutritional variables. The designed model is statistically significant and is indicated by the $R^{2}$ value of 0.99 . The optimized medium improved the production of ECP and is two folds higher in comparison with the basal medium.

Conclusions: Acinetobacter indicus M6 bacterium produces a novel and unique extracellular heteropolysaccharide with highly efficient antioxidant activity. GC-MS analyses elucidated the presence of quite uncommon $(1 \rightarrow 4)$-linked glucose, $(1 \rightarrow 4)$-linked mannose, and $(\rightarrow 4)-G l c N-(1 \rightarrow)$ glycosidic linkages in the backbone. The optimized medium improved the production of ECP and is two folds higher in comparison with the basal medium. The newly optimized medium could be used as a promising alternative for the overproduction of ECP.
\end{abstract}

Keywords: Extracellular polysaccharide, Antioxidant activity, Response surface methodology, Monosaccharide composition

\footnotetext{
* Correspondence: kodalividyaprabhakar@gmail.com

'Department of Biotechnology, Vikrama Simhapuri University, Kakutur,

Nellore A.P-524320, India

Full list of author information is available at the end of the article
}

\section{Springer Open}

(c) The Author(s). 2021 Open Access This article is licensed under a Creative Commons Attribution 4.0 International License, which permits use, sharing, adaptation, distribution and reproduction in any medium or format, as long as you give appropriate credit to the original author(s) and the source, provide a link to the Creative Commons licence, and indicate if changes were made. The images or other third party material in this article are included in the article's Creative Commons licence, unless indicated otherwise in a credit line to the material. If material is not included in the article's Creative Commons licence and your intended use is not permitted by statutory regulation or exceeds the permitted use, you will need to obtain permission directly from the copyright holder. To view a copy of this licence, visit http://creativecommons.org/licenses/by/4.0/. 


\section{Background}

Acinetobacter species produce medicinally and commercially important diverse group of molecules [1]. Extracellular polysaccharides (ECPs) are one of such important molecules. ECPs are long-chain, high molecular-mass polymers which have been reported to show antiulcer, immunomodulatory, antiviral, antioxidant, and various other biological activities [2,3]. These ECPs are the alternative class of biothickeners and also proved to have good emulsifying property apart from the texturepromoting property in various foods [4]. In some countries of the European Union (EU) and the United States of America (USA), where addition of synthetic texturepromoting agents in food and dairy products is prohibited, ECPs can successfully be used as food additives to enhance texture [5]. The ECPs are economically important because they can impart functional effects to foods. Depending on the monosaccharide composition, ECPs can be classified into homo (HoPSs) and heteropolysaccharides (HePSs). HoPSs consist of only one type of monosaccharide.

Recently, studies have been focused on antioxidant polysaccharides that can find potential applications in food industries [6]. Free radicals such as superoxide radical anion $\left(\mathrm{O}_{2}{ }^{--}\right)$, hydroxyl radical $(\mathrm{OH} \cdot)$, and other reactive oxygen species (ROS) are considered to be highly potent oxidants that can react with all biomacromolecules in living cells, and they may associate with carcinogenesis and mutagenesis [7]. ECPs were reported to have free radical scavenging activities [8]. Bacterial polysaccharides isolated from Pantoea agglomerans and Microbacterium terregens [9] showed pronounced antioxidant activities.

Considering the antioxidant activity and other therapeutic importance of the ECP, it is important to characterize the ECP structurally. Therefore, the monomeric composition of the ECP was identified by HPLC, and glycosidic linkages of the ECP were determined by GC-MS. HPLC is frequently used for both the qualitative and quantitative analysis of liberated monosaccharides after acid hydrolysis. HPLC with an ultraviolet (UV) detector or refractive index (RI) is an alternative method for quantitative determination of saccharides. Due to low sensitivity and inapplicability to gradient elution, HPLC with RI detector is less commonly used [10]. The alternative approach is HPLC with UV detector, which is highly sensitive and widely used for analysis and quantification of monomers. GC attached to a mass spectrometer is an efficient and widely applicable method for linkage analysis of methylated polysaccharides. Methylation analysis is an essential step for studying the linkage pattern of sugar residues. Depending on the mass spectra obtained, the glycosidic linkages are analyzed [11, 12].
The production of polymers is highly influenced by different factors such as nutritional variables and physical variables of the process, namely, temperature, $\mathrm{pH}$, RPM, dissolved oxygen concentration, and RPM [9]. Studies also reported that the growth and development of film formation depend on surface area, smoothness, flow velocity, and nutrients [13]. Very few reports are available on design fermentation medium through response surface methodology (RSM) optimization studies for production of ECPs [13]. Therefore, the present study aimed to design the low-cost fermentation medium for enhanced production of the ECP using RSM.

Considering the tremendous reported therapeutic and commercial potentials, the ECP molecule may be developed as a potential drug molecule in the near future. Establishing the structure-function relationship of the ECP molecule by elucidating its complete molecular structure on further chemical derivatizations and enzymatic digestions (with glucosidases) will enable to identify the right fragments of the large ECP molecule, responsible for important bioactive properties of therapeutic and commercial interests. This would also help to use the small fragments for specific therapeutic purposes, instead of using the whole molecule.

\section{Methods}

Extraction, purification, and quantification of extracellular polysaccharide

ECP-producing organism was isolated and identified as mentioned previously [14]. Ten milliliters of overnight culture was centrifuged, and $30 \mathrm{~mL}$ alcohol (95\%) was added to the supernatant. The mixture was shaken thoroughly and kept at $4{ }^{\circ} \mathrm{C}$ for overnight. The precipitated polymer was separated by centrifugation and dried to get crude ECP. The dried and crude powder $(10 \mathrm{mg})$ was dissolved in $1 \mathrm{~mL} 0.2 \mathrm{M} \mathrm{NaCl}$ buffer to a concentration of $10 \mathrm{~g} / \mathrm{L}$ and was filtered through a $0.22-\mu \mathrm{m}$ membrane filter, loaded onto a Sephadex G-100 column (Sigma Aldrich, St Louis, USA-50 $\times 1.5 \mathrm{~cm}$ ). The column was eluted with the same buffer at a flow rate of $0.5 \mathrm{~mL} / \mathrm{min}$, and $0.5 \mathrm{~mL}$ of fractions was collected. Total carbohydrate content of the fractions was determined by phenol-sulfuric acid method, and the carbohydrate content was measured by phenol sulfuric acid method [15].

\section{Antioxidant activity of the ECP}

The antioxidant potential of ECP was studied by superoxide radical scavenging assay by phenazine methosulfate (PMS)-nicotinamide adenine dinucleotide (NADH)Nitroblue tetrazolium chloride (NBT) system, 1,1-diphenyl-2-picrylhydrazyl (DPPH) radical scavenging activity [16]. Vitamin C was used as a positive control. 


\section{Hydroxyl radical scavenging activity of the ECP}

The hydroxyl radical scavenging activity of ECP was measured according to Liu et al. and Ren et al. [17, 18]. The hydroxyl radicals were generated in the L-ascorbic acid- $\mathrm{CuSO}_{4}$ system by reduction of $\mathrm{Cu}^{2+}$ and were assayed by the oxidation of cytochrome $\mathrm{C}$. In this experiment, hydroxyl radicals were generated in $3 \mathrm{~mL}$ of 0.15 $\mathrm{mM}$ sodium phosphate buffer ( $\mathrm{pH}$ 7.4), which included $100 \mu \mathrm{ML}$-ascorbic acid, $100 \mu \mathrm{M} \mathrm{CuSO} 4,12 \mu \mathrm{M}$ cytochrome $\mathrm{C}$, and the samples to be tested at different concentrations. The mixture was incubated at $25{ }^{\circ} \mathrm{C}$ for 90 min. The color change of cytochrome $\mathrm{C}$ was measured at $550 \mathrm{~nm}$. Thiourea was used as control, and glucose was used as negative control.

The inhibition rate of hydroxyl radical generation by thiourea was taken as $100 \%$.

The inhibition rate was calculated using the following equation:

$$
\text { Inhibition rate }(\%)=\left[\frac{T-T_{2}}{T-T_{1}}\right] \times 100
$$

where $T$ is the transmittance of hydroxyl radical $\left(\mathrm{OH}^{*}\right)$ generation system and $T_{1}$ and $T_{2}$ are the transmittance of control and test sample systems respectively.

\section{Superoxide $\left(\mathrm{O}_{2}{ }^{-}\right)$radical scavenging activity of the ECP}

Measurement of superoxide radical scavenging activity was done based on the method described by Ren et al. [18] and Nishimiki et al. [19]. To $1 \mathrm{~mL}$ of NBT solution $(156 \mu \mathrm{M}$ NBT in $100 \mathrm{mM}$ phosphate buffer, $\mathrm{pH} 7.4), 1$ $\mathrm{mL} \mathrm{NADH}$ solution $(468 \mu \mathrm{M}$ in $100 \mathrm{mM}$ phosphate buffer, $\mathrm{pH}$ 7.4) and $0.1 \mathrm{ml}$ of ECP in water were added and mixed well. The reaction was started by adding $100 \mu \mathrm{L}$ of PMS solution $(60 \mu \mathrm{M}$ PMS in $100 \mathrm{mM}$ phosphate buffer, $\mathrm{pH}$ 7.4) to the mixture. The reaction mixture was incubated at $25{ }^{\circ} \mathrm{C}$ for $5 \mathrm{~min}$, and the absorbance was measured at $560 \mathrm{~nm}$ against blank samples using a spectrophotometer, and vitamin $\mathrm{C}$ was used as positive control. Decreased absorbance of the reaction mixture indicated increased superoxide anion-scavenging activity.

The scavenging activity of superoxide radical (\%) was calculated from the following equation:

Superoxide radical scavenging activity (\%)

$$
=\left[1-\frac{A_{\text {Sample }}}{A_{\text {Blank }}}\right] \times 100
$$

where $A_{\text {Blank }}$ is the absorbance of the control reaction (containing all reagents except the test compound) and $A_{\text {Sample }}$ is the absorbance of the test compound.

\section{DPPH radical scavenging activity}

The free radical scavenging activity of ECP was measured by DPPH free radical scavenging assay. To $1 \mathrm{~mL}$ of $0.1 \mathrm{mM}$ solution of DPPH in ethanol, $3 \mathrm{ml}$ of ECP in water was added in different concentrations. After 30 min, absorbance was measured at $517 \mathrm{~nm}$ against blank. Radical scavenging activity was expressed as percentage inhibition of DPPH and estimated by the following equation [20]:

$$
\begin{aligned}
& \text { DPPH free radical scavenging activity }(\%) \\
& \quad=\left[1-\frac{A_{\text {Sample }}}{A_{\text {Blank }}}\right] \text { x100 }
\end{aligned}
$$

where $A_{\text {Blank }}$ is the absorbance of the control reaction (containing all reagents except the test compound) and $A_{\text {Sample }}$ is the absorbance of the test compound. Vitamin $\mathrm{C}$ was used as the positive control. All determinations were performed in triplicate. Decrease in the absorbance indicated the antioxidant activity.

\section{Compositional analysis of ECP}

HPLC analysis is a commonly used method to determine the monosaccharide composition of polysaccharides. The polysaccharides are hydrolyzed to get individual monomers and then labeled with anthranilic acid to increase the florescence for easy and accurate identification [21]. The sugar composition of the ECP was studied by high-performance liquid chromatography (HPLC) [7]. For specific determination of monosaccharides with high sensitivity, ECP was acid hydrolyzed and then derivatized in a simple step with excess anthranilic acid (2aminobenzoic acid) in the presence of sodium cyanoborohydride to give highly fluorescent-stable derivatives. The monosaccharide derivatives were completely separated from the excess reagent and from each other by HPLC on a $\mathrm{C}_{18}$ reversed-phase column using a butylamine-phosphoric acid-tetrahydrofuran mobile phase [2].

\section{Acid hydrolysis of ECP}

ECP isolated from $36 \mathrm{~h}$ culture was dissolved in deionized water and dialyzed against deionized water using $12 \mathrm{kDa}$ membrane at $4{ }^{\circ} \mathrm{C}$ for $24 \mathrm{~h}$ and then lyophilized. Ten milligrams of lyophilized ECP was hydrolyzed with $2 \mathrm{M}$ trifluoroacetic acid (TFA) for $6 \mathrm{~h}$ at $100{ }^{\circ} \mathrm{C}$. TFA was removed using rotary vacuum evaporator [22].

\section{Derivatization of monosaccharides with anthranilic acid}

The hydrolysates were derivatized by anthranilic acid reagent [21, 22]. Briefly, anthranilic acid reagent was prepared by dissolving anthranilic acid $(30 \mathrm{mg})$ and sodium cyanoborohydride in $1 \mathrm{~mL}$ of acetate-boric acidmethanol solution. The ECP hydrolysates were dissolved 
Table 1 Carbohydrate and protein contents of crude and pure ECP

\begin{tabular}{llll}
\hline S.No & Fraction & Total carbohydrate (\%) & Protein (\%) \\
\hline 1. & Crude ECP & $92 \pm 2$ & $0.9 \pm 0.3$ \\
2. & Purified ECP & $98 \pm 1$ & 0 \\
\hline
\end{tabular}

${ }^{a}$ Alcohol-precipitated ECP

${ }^{\mathrm{b}}$ Purified ECP by gel filtration chromatography

in $100 \mu \mathrm{L}$ of $1 \%$ sodium acetate, and an aliquot of $50 \mu \mathrm{L}$ was transferred to a new screw-cap freeze vial. Samples were mixed with $100 \mu \mathrm{L}$ of anthranilic acid and capped tightly. Vials were heated at $80{ }^{\circ} \mathrm{C}$ for $60 \mathrm{~min}$. After cooling, the samples were made up to $1 \mathrm{~mL}$ with solvent $\mathrm{A}$ (2\% 1-butylamine, $0.5 \%$ phosphoric acid, and $1 \%$ tetrahydrofuran) for analysis in HPLC.

\section{HPLC analysis of anthranilic acid-monosaccharide derivatives}

Monosaccharide derivatives were analyzed in Agilent 1000 series HPLC (Agilent Technologies, Model No.1100). A reversed-phase $\mathrm{C}_{18}$ column (ZORBAX 300 SB-C18, $5 \mu \mathrm{m}, 4.6 \times 250 \mathrm{~mm}$, USA) and 1-butylaminephosphoric acid-tetrahydrofuran mobile phase system consisting of solvents A and B were used for this analysis. Solvent A comprises of $0.2 \%$ 1-butylamine, $0.5 \%$ phosphoric acid, and $1 \%$ tetrahydrofuran in water, and solvent $\mathrm{B}$ consisted of equal parts of solvent $\mathrm{A}$ and acetonitrile. The separations were carried out at $24{ }^{\circ} \mathrm{C}$ using a flow rate of $1 \mathrm{~mL} / \mathrm{min}$, and $20 \mathrm{~mL}$ of each sample was injected. An UV detector was used to detect the derivatized monosaccharides. The gradient program was used according to [21].

\section{Determination of monosaccharide linkage analysis of the ECP molecule GC-MS methylation analysis}

A solution of ECP $(5 \mathrm{mg})$ in dimethyl sulfoxide $(0.5 \mathrm{~mL})$ was permethylated by adding finely powdered $\mathrm{NaOH}$ $(20 \mathrm{mg})$ and methyl iodide $(0.1 \mathrm{~mL})$. Then, the mixture was sonicated for $15 \mathrm{~min}$. The permethylated ECP was extracted with $\mathrm{CHCl}_{3}(1 \mathrm{~mL})$ and $\mathrm{H}_{2} \mathrm{O}(3 \mathrm{~mL}) . \mathrm{CHCl}_{3}$ phase was separated and dried under $\mathrm{N}_{2}$ and hydrolyzed in $2 \mathrm{M}$ TFA at $100^{\circ} \mathrm{C}$ for $1 \mathrm{~h}$. The hydrolyzed ECP was reduced with $50 \mathrm{mM} \mathrm{NaBH}_{4}$ at room temperature for 4 $\mathrm{h}$ and evaporated three times from a mixture of acetic acid/methanol (1:1) followed by acetylation with 50:50 acetic anhydride/pyridine at $100{ }^{\circ} \mathrm{C}$ for $90 \mathrm{~min}$. Alditol acetates of the methylated sugars were analyzed by Shimadzu GCMS-QP2010. The temperature program and other column conditions were used according to Kim et al. $[23,24]$.

\section{Optimization studies of ECP production Production of ECP in shake flask}

Luria Bertani medium was inoculated with Acinetobacter indicus M6, incubated for $48 \mathrm{~h}$ at $160 \mathrm{rpm}$ at room temperature. Effect of salt, carbon, and nitrogen source on ECP production has been studied by varying

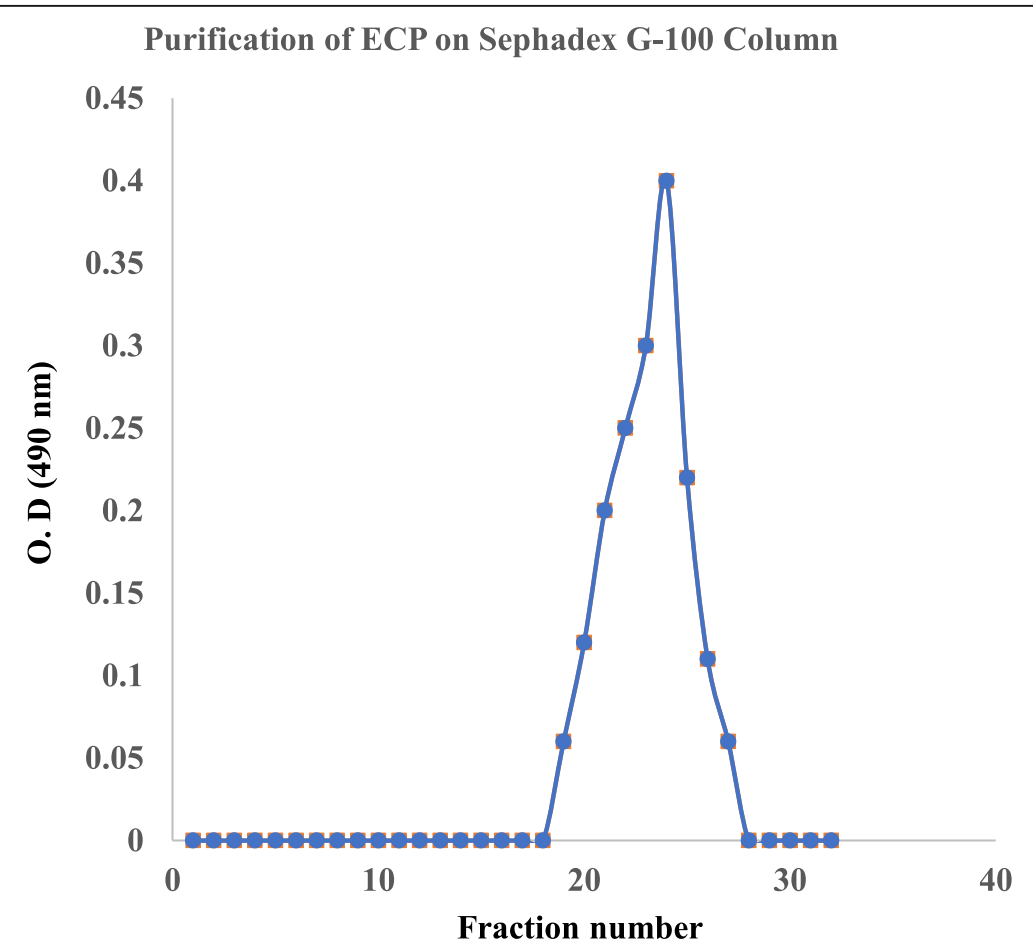

Fig. 1 Purification of ECP on Sephadex G-100 Column. $10 \mathrm{mg} / \mathrm{ml}$ was loaded and $0.5 \mathrm{ml}$ was collected 


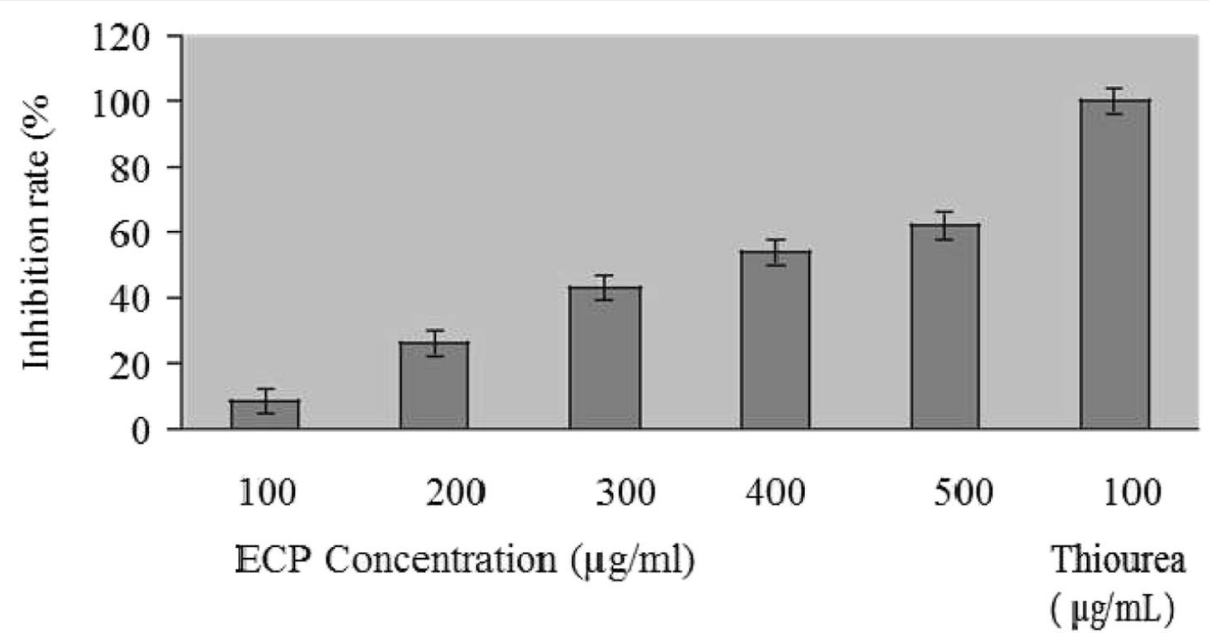

Fig. $2 \mathrm{OH}$ radical scavenging activity of the ECP. Values are means of triplicates \pm SD. The rate of inhibition of hydroxyl radical generation by thiourea $(100 \mu \mathrm{g} / \mathrm{ml})$ was taken $100 \%$

concentrations of $\mathrm{MgSO}_{4}$, glucose, and yeast extract. ECP production was expressed in terms of total carbohydrate concentration spectrophotometrically $(490 \mathrm{~nm})$ [18]. ECP extraction method was followed as mentioned above.

\section{Optimization of nutritional variables by RSM}

Response surface methodology (RSM) is a more convenient tool for designing experiments, plotting models, evaluating the effects of factors, and exploring optimum conditions of factors for significant responses. RSM is also used for optimization of prominent varieties of fermentation media and studying interactions among various bioprocess parameters with the minimum number of experiments $[25,26]$. In the present experimentation, production of ECP in shake flask culture with Acinetobacter indicus M6 was found to be higher when compared to other bacterial species. Therefore, this strain has been considered as a potential bacterium for ECP production and hence it has been aimed to develop a suitable medium for enhanced production of ECP through optimization of nutrient component concentrations by response surface methodology (RSM). Fermentation medium variables such as glucose (A), yeast extract (B), and $\mathrm{MgSO}_{4}(\mathrm{C})$ were optimized using the Design Expert software (Version 7.0.0, Stat-Ease Inc., Minneapolis, USA). The variables range from low $(-1)$ to high $(+1)$ used in the study are presented in Table 1.The impact of nutritional components on production and regression analysis of experimental data was carried out; further, the threedimensional surface plots were drawn. The model was validated through the conduction of an experiment at predicted variables as suggested by the designed statistical model [27].

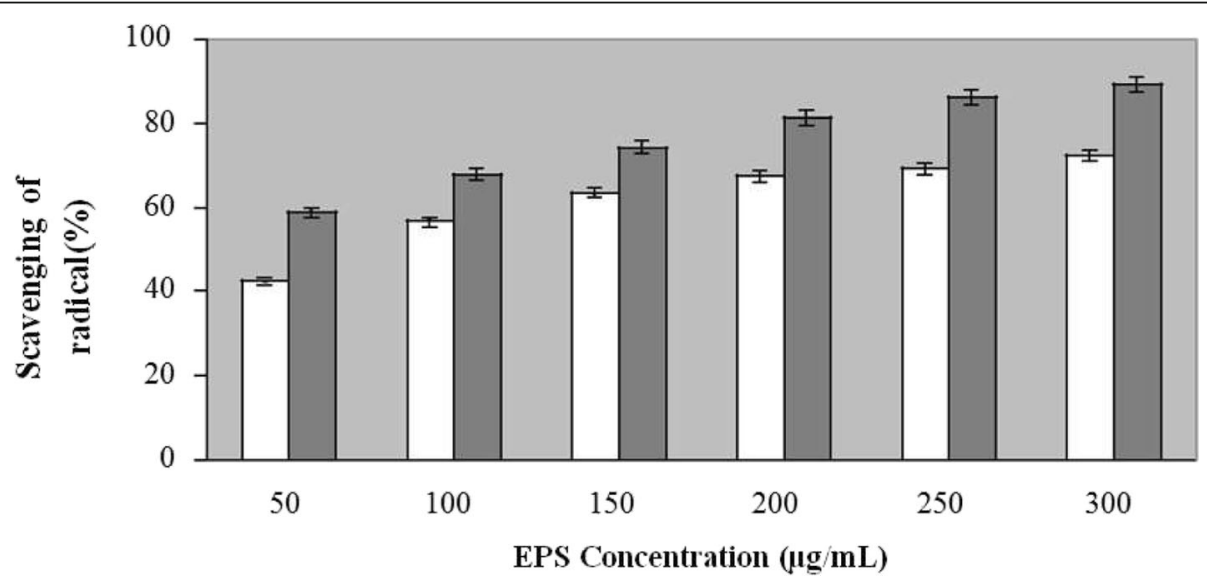

Fig. 3 Scavenging activity of ECP against superoxide radical generated in PMS/NADH system with vitamin C used as positive control. Values are means of triplicates \pm SD. White bar indicates ECP, Black bar indicates Vitamin C 


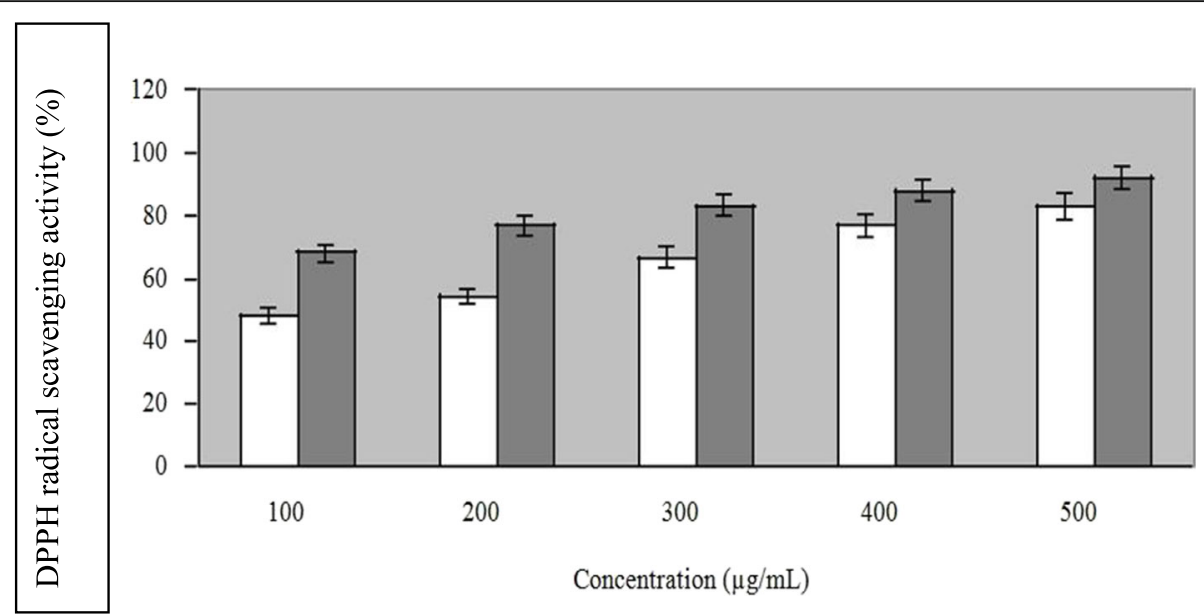

Fig. 4 Scavenging effects of ECP against 1, 1-diphenyl-2-picryl hydrazyl radical with vitamin $C$ used as positive control. Values are means of triplicates \pm SD. White bar indicates ECP, Black bar indicates Vitamin C

\section{Results}

\section{Extraction, purification, and quantification of the ECP}

The ECP produced by Acinetobacter indicus M6 was extracted as described previously and then purified. The gel filtration chromatogram (Fig. 1) showed that the elution of the ECP starts at the 18th fraction and ended at the 28th fraction. There was no protein content in polysaccharide fractions, indicating that the ECP had no associated proteins. The carbohydrate and protein contents of the crude and purified ECP are listed in Table 1 . While the total sugar content $(\%, w / w)$ of the
ECP was found to increase by $6 \%$ on purification, the $\%$ content of the contaminating proteins decreased to zero from a value of $0.9 \%$. The total carbohydrate and protein concentrations were observed to be $380 \mu \mathrm{g} / \mathrm{mL}$ and $150 \mu \mathrm{g} / \mathrm{mL}$ respectively.

\section{Antioxidant activity of the ECP \\ Hydroxyl radical scavenging assay of the ECP}

The hydroxyl radical scavenging activity of ECP (ranging from 100 to $500 \mu \mathrm{g} / \mathrm{mL}$ ) by ascorbic acid- $\mathrm{Cu}^{2+}$. cytochrome $\mathrm{C}$ system is shown in Fig. 2. The

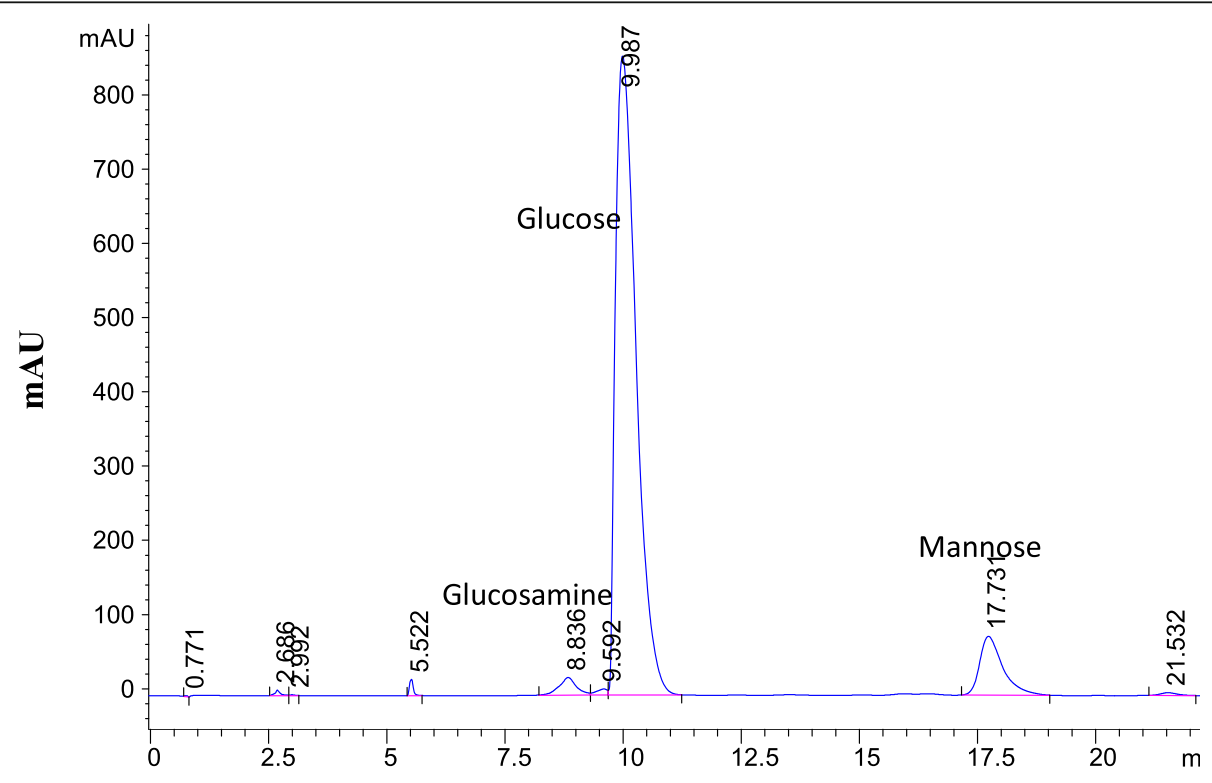

Retention Time (min)

Fig. $5 \mathrm{HPLC}$ analysis of hydrolyzed ECP. (Glucose is a major monomeric unit; mannose and glucosamine are the minor units) 
Table 2 Results of the analysis of GC-MS

\begin{tabular}{ll}
\hline Fragments $^{\mathbf{a}}$ & $\begin{array}{l}\text { Mode of } \\
\text { Linkage }\end{array}$ \\
\hline 1,2,4-tri-O-acetyl-3,6-di-O-methyl-D-mannitol & $(\rightarrow 1,2)-$ Man-(4 $\rightarrow$ \\
1,4-di-O-acetyl-2,4,6-tri-O-methyl-D-glucitol & $(\rightarrow 1)-G l c-(4 \rightarrow$ \\
1,4,6-di-O-acetyl-3-mono-O-methyl-2-amino-D- & $(\rightarrow 1,4)-G \mid c N-(6 \rightarrow$ \\
glucitol
\end{tabular}

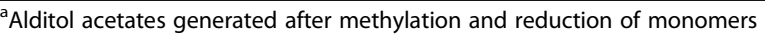

scavenging activity of the ECP when correlated with its concentration showed that the activity increased till a concentration of $500 \mu \mathrm{g} / \mathrm{mL}$ and remained stable thereafter. ECP showed considerable hydroxyl radical scavenging activity of $59 \%$ at the concentration of $500 \mu \mathrm{g} / \mathrm{mL}$. Here, in these experiments, the rate of inhibition of hydroxyl radical generation by thiourea (as a positive control) at a concentration of $100 \mu \mathrm{g} / \mathrm{mL}$ was taken as $100 \%$, and glucose was used as negative control.

\section{Superoxide $\left(\mathrm{O}_{2}{ }^{--}\right)$radical anion scavenging activity of the ECP}

The decrease in absorbance at $560 \mathrm{~nm}$ with the addition of ECP indicates the consumption of superoxide radical in the reaction mixture (Fig. 3). The ECP showed noticeable superoxide radical scavenging activity with increasing concentration ranging from 50 to $300 \mu \mathrm{g} / \mathrm{mL}$. The maximum scavenging activity of the ECP was estimated to be $72.4 \%$ where reference compound vitamin C showed $90 \%$ at concentration of $300 \mu \mathrm{g} / \mathrm{mL}$.

\section{DPPH free radical scavenging activity}

This method is based on the reduction of methanolic $\mathrm{DPPH}^{*}$ solution in the presence of a hydrogen-donating antioxidant, due to the formation of the non-radical form $\mathrm{DPPH}-\mathrm{H}$ by the reaction. $\mathrm{DPPH}^{-}$is a stable free radical and accepts an electron or hydrogen radical to become a stable diamagnetic molecule [21, 22]. The antioxidant of ECP was determined by $\mathrm{DPPH}^{\circ}$ radical scavenging activity assay. Vitamin $\mathrm{C}$ was used as standard. Figure 4 illustrates the $\mathrm{DPPH}^{*}$ radical scavenging ability of ECP which increased with increasing concentration of ECP ranging from 100 to $500 \mu \mathrm{g} / \mathrm{mL}$. Vitamin $\mathrm{C}$ and ECP showed $92 \%$ and $72.2 \% \mathrm{DPPH}^{\circ}$ radical scavenging activity respectively at $500 \mu \mathrm{g} / \mathrm{mL}$ concentration.
In terms of this antioxidant activity, the antioxidant activity of the ECP and the standard were comparable.

\section{Compositional analysis of the ECP}

The ECP after being hydrolyzed and derivatized with anthranilic acid was analyzed for its sugar composition by HPLC. The HPLC chromatogram (Fig. 5) showed that the ECP was a heteropolysaccharide, composed of glucose and glucosamine [22]. In terms of peak area, glucose (retention time $9.9 \mathrm{~min}$ ) was the major monosaccharide, whereas glucosamine (retention time 8.8 $\mathrm{min}$ ), and mannose (retention time 17.7) were the minor ones.

\section{Determination of linkages between the monosaccharide units}

The sugar linkages in alditol acetates of the methylated sugars of the ECP were elucidated by GC-MS analysis. Methylation analysis is a widely used method for determining polysaccharide structure $[28,29]$. However, reductive cleavage depolymerization has several advantages compared to standard methylation analysis, and it is an effective method for structural characterization of complex carbohydrates, which have different sugar residues [27]. The alditol derivatives were 1,2,4-tri-O-acetyl-3,6-tri- $O$ methyl-D-mannitol; 1,4-di-O-acetyl-2,4,6-tri-O-methyl-Dglucitol; 1,4,6-di-O-acetyl-3-mono-O-methyl-2-amino-Dglucitol (Tables 2 and 3), revealed that $(1 \rightarrow 4)$-linked glucose, $(1 \rightarrow 4)$ linked mannose, $(\rightarrow 4)$-GlcN- $(1 \rightarrow)$. The linkages between the monosaccharides were predicted according to Bjorndal et al. [12, 27]. Based on the HPLC and GC-MS data, the probable structure of the ECP is given in Figs. 6 and 7.

\section{Optimization studies of ECP production Central composite design for medium optimization}

Response surface methodology (RSM) is a collection of mathematical and statistical techniques widely used to determine the effects of several variables and to optimize different biotechnological processes [26]. The central composite design (CCD) was adopted for optimization of medium components such as glucose, yeast extract, and $\mathrm{MgSO}_{4}$. The experimental results of $\mathrm{CCD}$ for enhancing the yield of ECP are shown in Table 4.

The response $(\mathrm{Y})$ fitted with the second-order polynomial equation

Table 3 GC data showing the number of peak traces

\begin{tabular}{lll}
\hline Fragments & Mode of linkage & Major mass fragments $(\mathbf{m} / \mathbf{z})$ peak traces \\
\hline 1,2,4-tri-O-acetyl-3,6-di-O-methyl-D-mannitol & $(\rightarrow 1,2)-M a n-(4 \rightarrow$ & $104,113,129,147,161,181,191,197$ \\
1,4-di-O-acetyl-2,4,6-tri-O-methyl-D-glucitol & $(\rightarrow 1)-G l c-(4 \rightarrow$ & $103,119,130,151,177,193,196$ \\
1,4,6-di-O-acetyl-3-mono-O-methyl-2-amino-D-glucitol & $(\rightarrow 1,4)$-GlcN-(6 $\rightarrow$ & $110,117,131,147,163,181,191,197$ \\
\hline
\end{tabular}



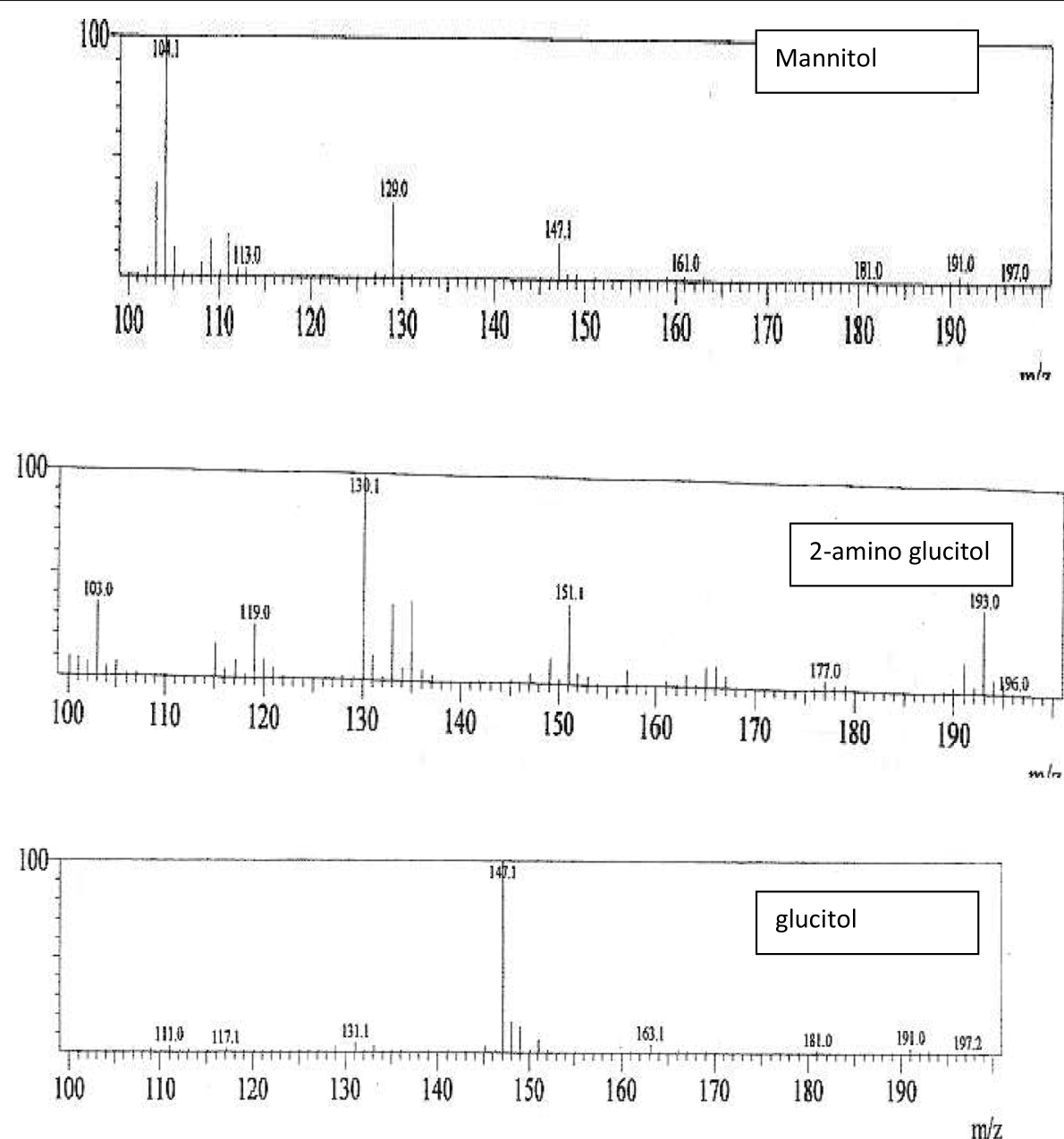

Fig. 6 Mass spectra obtained by GC-MS analysis obtained by Shimadzu GC-MS QP 2010 using ZB-1 column

$R_{1}=+2.54+0.14 A-0.032 B-0.083 C+0.014 A B-0.13 \mathrm{AC}$

$$
-0.079 B C-.59 A^{2}-1.23 B^{2}-0.11 C^{2}
$$

$R_{1}$ represents the response for ECP production, whereas glucose, yeast extract, and $\mathrm{MgSO}_{4}$ are represented by variables $A, B$, and $C$, respectively, and the $R^{2}$ coefficient value of 0.99 suggested that predicted model was significant (Table 5). The Model $F$-value of 154.37 implies the model is significant. In this case, $A, C, \mathrm{AC}, A^{2}$, and $B^{2}$ are significant model terms (Table 6). The combinational effect of
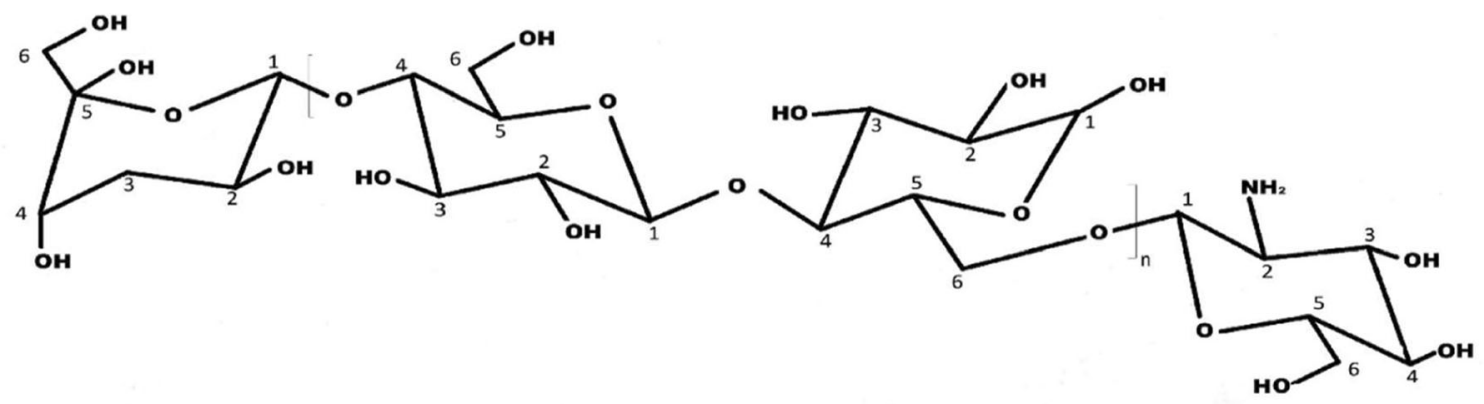

Mannose $\alpha(1 \rightarrow 4)$ [Glucose $\beta(1 \rightarrow 4)$ Glucose]n $\alpha(1 \rightarrow 6)$ Glucosamine

Fig. 7 The probable structure of ECP 
Table 4 The nutritional variables selected for optimization study

\begin{tabular}{lll}
\hline S.No. & Nutritional variables & ${ }^{\text {a Range in } \mathbf{~} / \mathbf{L}}$ \\
\hline 1 & Glucose (A) & $5-15$ \\
2 & Yeast extract (B) & $5-10$ \\
3 & $\mathrm{MgSO}_{4}$ (C) & $0.2-0.4$ \\
\hline${ }^{a}$ Concentration ranges &
\end{tabular}

nutritional variables on the production of ECP was analyzed from the 3-D response surface curves as shown in Fig. 8.

\section{Validation of RSM model}

The RSM model is validated by conducting an experiment at best-predicted solution for production of ECP. Under optimized conditions, the ECP yield reached 2.21 $\mathrm{g} / \mathrm{L}$ from Acinetobacter indicus M6, which is almost near to the RSM predicted value (Table 7).

\section{Discussion}

Acinetobacter M6 produces ECP in substantial quantities $(2.21 \mathrm{~g} / \mathrm{L})$. This quantity is considerably higher when compared to other reported bacterial ECPs. As far as our knowledge, there is no report available on ECP from Acinetobacter indicus M6 bacterium. ECP from this marine bacterium may be beneficial because few of the
ECPs have been reported to have emulsification property which can find potential applications in the reduction of marine water pollution $[27,28]$. The purified ECP shows significant antioxidant activities when compared to the standard antioxidant active compound (Vit C). Free radicals such as superoxide radical, hydroxyl radical, and other reactive oxygen species (ROS) are associated with multistage carcinogenesis and mutagenesis $[29,30]$. The results of present study have demonstrated that ECP was effective in scavenging superoxide, hydroxyl, and DPPH radicals in a concentration-dependent fashion. There are very few reports available on antioxidant activities of bacterial ECPs. However, this is the first report on antioxidant and free radical scavenging activities of an ECP from Acinetobacter indicus M6. Hence, the ECP may be developed as a potential antioxidant molecule after studying various toxicological studies. The monosaccharides in the ECPs are actually potent reductive agents as they have a hidden aldehyde moiety [31]. The antioxidant mechanism of polysaccharides may thus be attributed to the reductive nature of the monosaccharides owing to the presence of - $\mathrm{CHO}$ group as these polysaccharides such as ECPs are not proton-donors. The mechanism of free-radical scavenging of polysaccharides is still not fully understood. The results of the present

Table 5 Actual data for design of experiments

\begin{tabular}{|c|c|c|c|c|c|}
\hline \multirow[t]{2}{*}{ S.No. } & \multirow[t]{2}{*}{ Glucose } & \multirow{2}{*}{$\begin{array}{l}\text { Yeast } \\
\text { extract }\end{array}$} & \multirow[t]{2}{*}{$\mathrm{MgSO}_{4}$} & \multicolumn{2}{|c|}{ Production of biosurfactant in $\mathrm{g} / \mathrm{L}$} \\
\hline & & & & Experimental $^{\mathrm{a}}$ & Predicted $^{\mathrm{b}}$ \\
\hline 1. & 15 & 10 & 0.3 & 1.95 & 2.1 \\
\hline 2. & 5 & 15 & 0.4 & 0.36 & 0.39 \\
\hline 3. & 10 & 10 & 0.3 & 2.51 & 2.54 \\
\hline 4. & 15 & 15 & 0.2 & 1.08 & 1.03 \\
\hline 5. & 5 & 5 & 0.4 & 0.63 & 0.64 \\
\hline 6. & 10 & 10 & 0.3 & 2.54 & 2.54 \\
\hline 7. & 10 & 10 & 0.4 & 2.36 & 2.34 \\
\hline 8. & 10 & 10 & 0.3 & 2.63 & 2.54 \\
\hline 9. & 10 & 5 & 0.3 & 1.22 & 1.34 \\
\hline 10. & 15 & 5 & 0.4 & 0.66 & 0.63 \\
\hline 11. & 10 & 15 & 0.3 & 1.25 & 1.28 \\
\hline 12. & 5 & 15 & 0.2 & 0.46 & 0.45 \\
\hline 13. & 10 & 10 & 0.3 & 2.65 & 2.54 \\
\hline 14. & 15 & 5 & 0.2 & 0.98 & 0.91 \\
\hline 15. & 10 & 10 & 0.3 & 2.56 & 2.54 \\
\hline 16. & 5 & 10 & 0.3 & 1.8 & 1.81 \\
\hline 17. & 10 & 10 & 0.3 & 2.65 & 2.54 \\
\hline 18. & 5 & 5 & 0.2 & 0.42 & 0.38 \\
\hline 19. & 15 & 15 & 0.4 & 0.44 & 0.44 \\
\hline 20. & 10 & 10 & 0.2 & 2.34 & 2.51 \\
\hline
\end{tabular}

${ }^{a}$ Experimental result of biosurfactant production at the mentioned nutrient concentrations

${ }^{\mathrm{b}} \mathrm{RSM}$ predicted value of biosurfactant production at the mentioned nutrient concentrations 
Table 6 ANOVA for response surface quadratic model

\begin{tabular}{llllll}
\hline Source & Sum of squares & df & Mean square & F-value & $\boldsymbol{p}$-value Prob $>\boldsymbol{F}$ \\
\hline Model & 15.38 & 9 & 1.71 & 154.37 & $<0.0001$ \\
A-glucose & 0.21 & 1 & 0.21 & 18.73 & 0.0015 \\
B-yeast extract & 0.01 & 1 & 0.01 & 0.92 & 0.3589 \\
$\mathrm{C}-M g S O_{4}$ & 0.07 & 1 & 0.07 & 6.22 & 0.0318 \\
$\mathrm{AB}$ & 0.00 & 1 & 0.00 & 0.14 & 0.7194 \\
$\mathrm{AC}$ & 0.14 & 1 & 0.14 & 12.92 & 0.0049 \\
$\mathrm{BC}$ & 0.05 & 1 & 0.05 & 4.48 & 0.0604 \\
$\mathrm{~A}^{2}$ & 0.95 & 1 & 0.95 & 85.92 & $<0.0001$ \\
$\mathrm{~B}^{2}$ & 4.15 & 1 & 4.15 & 374.61 & $<0.0001$ \\
$\mathrm{C}^{2}$ & 0.04 & 1 & 0.04 & 3.18 & 0.1048 \\
Residual & 0.11 & 10 & 0.01 & & \\
Lack of fit & 0.09 & 5 & 0.02 & 4.95 & 0.0519 \\
Pure error & 0.02 & 5 & 0.00 & & Not significant \\
Cor total & 15.50 & 19 & & & \\
\hline
\end{tabular}

aff $p$-value of a parameter is $<0.05$, the effect of that parameter is significant

study have demonstrated that ECP is effective in scavenging superoxide, hydroxyl, and DPPH radicals in a concentration-dependent fashion. There are a very few reports available on antioxidant activities of bacterial ECPs. However, this is the first report on antioxidant and free radical scavenging activities of an ECP from Acinetobacter indicus M6. HPLC analysis indicated that ECP was a heteropolymer composed of glucose, mannose, and glucosamine. The presence of these monomers makes the heteropolymer unique, and this monomeric combination was not found in any other reported ECPs. GC-MS data of alditol derivatives revealed that $(1 \rightarrow 4)$ linked glucose, $(1 \rightarrow 4)$-linked mannose, and $(\rightarrow 4)$-GlcN$(1 \rightarrow)$ were present in the ECP. Presence of these linkages also makes our ECP unique and novel, and the predicted structure is given in Fig. 7 [32]. ECP from Acinetobacter indicus M6 was found to be a structurally complex but novel molecule for its unique
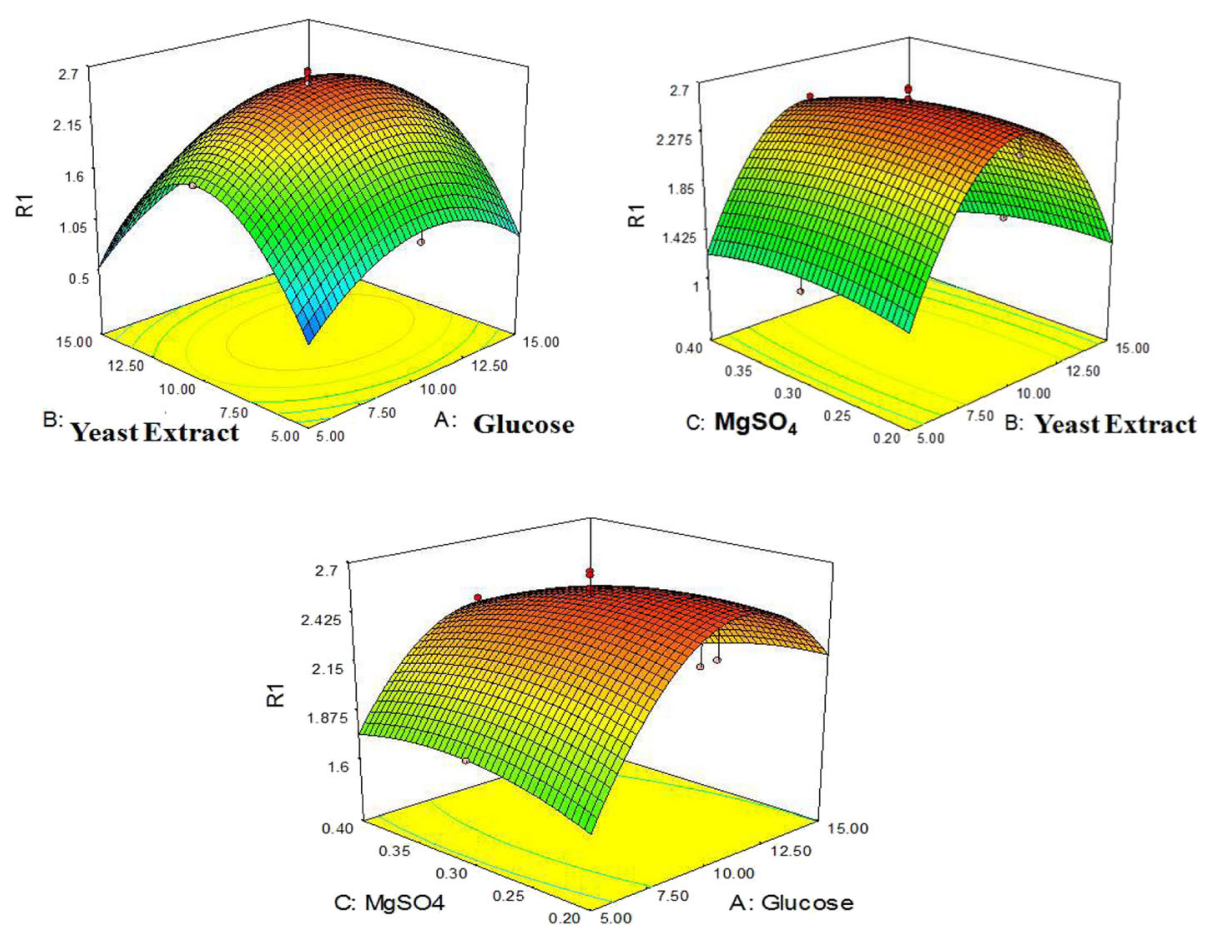

Fig. 8 3D graphs showing the combinational interaction of variables on production of ECP 
Table 7 Validation of RSM model for ECP production

\begin{tabular}{|c|c|c|c|c|c|}
\hline \multirow[t]{2}{*}{ S.No. } & \multirow{2}{*}{$\begin{array}{l}\text { Glucose } \\
\text { (A), g/L }\end{array}$} & \multirow{2}{*}{$\begin{array}{l}\text { Yeast } \\
\text { extract } \\
\text { (B), g/L }\end{array}$} & \multirow{2}{*}{$\begin{array}{l}\mathrm{MgSO}_{4} \\
\text { (C), } \mathrm{g} / \mathrm{L}\end{array}$} & \multicolumn{2}{|l|}{ ECP production $\left(R_{1}\right), g / L$} \\
\hline & & & & RSM model predicted & Experimental \\
\hline 1 & 15 & 10.12 & 0.2 & 2.19 & 2.21 \\
\hline
\end{tabular}

monosaccharide composition and the glycosidic linkages between the monomeric units. This unique combination of the monosaccharides and unusual glycosidic linkages between them make our ECP novel. To undertake a holistic approach towards critically establishing the structure-function relationship of the ECP molecule by elucidating its complete molecular structure on further chemical derivatizations and enzymatic digestions (with glucosidases), so as enable us to identify the right fragments of the large ECP molecule, responsible for each of its important bioactive properties of therapeutic and commercial interests $[27,33]$. This would also help us to use the small fragments for specific therapeutic purposes, instead of using the whole molecule [34, 35]. However, the complete structural elucidation may be performed by other sophisticated techniques like NMR and ESI-MS which is the scope of the present study. The optimized medium improved the production of ECP and is two folds higher in comparison with the basal medium.

\section{Conclusion}

ECP produced by marine bacterium was purified and found to be a heteropolymer composed of glucose as a major monomer, and mannose and glucosamine were minor monomers, and this makes ECP unique in terms of its composition. GC-MS analyses elucidated the presence of quite uncommon $(1 \rightarrow 4)$-linked glucose, $(1 \rightarrow 4)$ linked mannose, and $(\rightarrow 4)$-GlcN- $(1 \rightarrow)$ glycosidic linkages in the backbone. The purified ECP has shown significant antioxidant activity. The detailed mechanisms of actions of the ECP molecule for its significant antioxidant activities need to be elucidated to develop the whole ECP molecule or the suitable fragments of it into prospective drug candidates. This requires a lot of basic research inputs. The production of ECP reached $2.21 \mathrm{~g} / \mathrm{L}$ after the optimization of nutritional variables. The designed model is statistically significant and is indicted by the $R^{2}$ value of 0.99 . The optimized medium improved the production of ECP and is two folds higher in comparison with the basal medium. As a long-term future scope and perspective, it would be prudent to scale the optimal process up to a pilot plant scale for consistent production of this important bioactive ECP molecule in large quantities. Though there are reports available on bacterial ECPs, this is the first report on ECP from Acinetobacter indicus M6. Unique monosaccharide composition and the glycosidic linkages between the monomeric units of the ECP markedly differ with the reported ECPs.

Considering the unique monosaccharide composition and significant antioxidant activity, the ECP may be developed as a drug molecule. The ECP is a promising antioxidant, and it can be used as an additive in food, pharmaceutical, and cosmetic preparations. The relationship between structure of ECP and antioxidant activity and also elucidation of its antioxidant mechanism at the molecular level will improve its biological activities by chemical modifications, one of the important implications of this study.

\section{Abbreviations \\ ECP: Extracellular polysaccharide; DPPH: 1,1-diphenyl-2 picryl hydrazyl; RSM: Response surface methodology}

\section{Acknowledgements \\ Prof. G. Vijay Ananda Kumar Babu, Head, Department of Biotechnology, VSU for providing the facilities.}

\section{Authors' contributions}

RTCh carried out the isolation and purification of the ECP. APK studied the antioxidant activity of the ECP. NV is involved in the HPLC analysis. VTC and MK helped in GC-MS part of the structural analysis. JBD is involved in optimization studies. VPK is the main author involved in the design and analysis of the whole study. All authors have read and approved the manuscript.

\section{Funding}

Department of Biotechnology (DBT), Ministry of Science and Technology, Govt. of India for financial support (F. No. BT/PR/7952/AAQ/3/642/2013) and DST-FIST-LSI-595 (LSI-026) for providing facility.

Availability of data and materials

The data is available and it will be provided to the editor if required.

\section{Declarations}

Ethics approval and consent to participate

This work is not involved in animal or human models. Hence, ethical approval is not required.

\section{Consent for publication}

Not applicable.

\section{Competing interests}

The authors declare no competing interest.

\section{Author details}

'Department of Biotechnology, Vikrama Simhapuri University, Kakutur, Nellore A.P-524320, India. ²Department of Biotechnology, VFSTR University, Vadlamudi, Guntur A.P-522213, India. ${ }^{3}$ SRR and CVR Government Degree College, Machavaram, Vijayawada A.P-520010, India. 
Received: 23 July 2020 Accepted: 16 February 2021

Published online: 12 March 2021

\section{References}

1. Shabtai Y (1990) Production of exopolysaccharides by Acinetobacter strains in a controlled fed-batch fermentation process using soap stock oil (SSO) as carbon source. Int J Biol Macromol 12(2):145-152

2. Welman AD, Maddox IS (2003) Exopolysaccharides from lactic acid bacteria: perspectives and challenges. Trends Biotechnol 21(6):269-274

3. Naidu AS, Bidlack WR, Clemens RA (1999) Probiotic spectra of lactic acid bacteria (LAB). Crit Rev Food Sci Nutr 39(1):13-126

4. Ashtaputre AA, Shah AK (1995) Emulsifying property of a viscous exopolysaccharide from Sphingomonas paucimobilis. World J Microbiol Biotechnol 11:219-222

5. De Vuyst L, Bart D (1999) Heteropolysaccharides from lactic acid bacteria. FEMS Microbiol Rev 23:153-177

6. Kishk YFM, Al-Sayed HMA (2007) Free-radical scavenging and antioxidative activities of some polysaccharides in emulsions. LWT Food Sci Technol 40: 270-277

7. Sun C, Wang JW, Fang L, Gao XD (2004) Free radical scavenging and antioxidant activities of EPS2, an exopolysaccharide produced by a marine filamentous fungus Keissleriella sp.YS 4108. Life Sci 75:1063-1073

8. Halliwell B, Gutteridge JMC (1986) Oxygen free radicals and iron in relation to biology and medicine: some problems and concepts. Arch Biochem Biophys 246:501-514

9. Reddy AR, Peele KA, Krupanidhi S, Kodali VP, Venkateswarulu TC (2018) Production of polyhydroxybutyrate from Acinetobacter nosocomialis RR20 strain using modified mineral salt medium: a statistical approach. Int Environ Sci Technol 16(3):6447-6452

10. Wang QJ, Fang YZ (2004) Analysis of sugars in traditional Chinese drugs. J Chromatogr B 812:309-324

11. Donlan RM, Costerton JW (2002) Biofilms: survival mechanisms of clinically relevant microorganisms. Clin Microbiol Rev 15(2):167-193

12. Bjorndal H, Hellerqvist CG, Lindberg B, Svensson SA (1970) Gas-liquid chromatography and mass spectrometry in methylation analysis of polysaccharides. Chem Int 9(8):610-618

13. Gruter M, Leeflang BR, Kuiper J, Kamerling JP, Vliegenthart JF (1993) Structural characterisation of the exopolysaccharide produced by Lactobacillus delbrückii subspecies bulgaricus rr grown in skimmed milk. Carbohydr Res 239:209-226

14. Peele KA, Ch VRT, Kodali VP (2016) Emulsifying activity of a biosurfactant produced by a marine bacterium. 3Biotech 6(2):177-180

15. Dubois M, Gilles KA, Hamilton JK, Pebers PA, Smith F (1956) Calorimetric method for determination of sugars and related substances. Anal Chem 28: 350-356

16. Wang H, Dong $X$, Zhou GC, Cai L, Yao WB (2008) In vitro and in vivo antioxidant activity of aqueous extract from Choerospondias axillaris fruit. Food Chem 106:888-895

17. Liu F, Ng TB (2000) Antioxidative and free radical scavenging activities of selected medicinal herbs. Life Sci 66:725-735

18. Ren D, Jiao Y, Yang X, Yuan L, Guo J, Zhao Y (2015) Antioxidant and antitumor effects of polysaccharides from the fungus Pleurotus abalonus. Chem Biol Interact 237:166-174

19. Nishimiki M, Rao NA, Yagi K (1972) The occurrence of superoxide anion in the reaction of reduced phenazine methosulfate and molecular oxygen. Biochem Biophys Res Commun 46:849-853

20. Sokmena M, Angelovab M, Krumovab E, Pashovab S (2005) In vitro antioxidant activity of polyphenol extracts with antiviral properties from Geranium sanguineum L. Life Sci 76:2981-2993

21. Anumula KR (1994) Quantitative determination of monosaccharides in glycoproteins by high-performance liquid chromatography with highly sensitive fluorescence detection. Anal Biochem 220(2):275-283

22. Anumula KR, Dhume ST (1998) High resolution and high sensitivity methods for oligosaccharide mapping and characterization by normal phase high performance liquid chromatography following derivatization with highly fluorescent anthranilic acid. Glycobiol 8(7):685-694

23. Kim SJ, Kim BG, Parka HU, Yim JH (2016) Cryoprotective properties and preliminary characterization of exopolysaccharide (P-Arcpo 15) produced by the Arctic bacterium Pseudoalteromonas elyakovii Arcpo 15. Prep Biochem Biotechnol 46:261-266
24. Maheswari P, Mahendran S, Sankaralingam S, Sivakumar N (2019) In vitro antioxidant activity of exopolysaccharide extracted from marine sediment soil bacteria. Res J Pharm Tech 12(9)

25. Bomfim VB, Neto JHL, Leite KS, Vieira EA (2020) Partial characterization and antioxidant activity of exopolysaccharides produced by Lactobacillus plantarum CNPC003. Food Sci Tech 127:109349

26. Lin SM, Baek CY, Jung JH, Kim WS, Song HY, Lee JH, Ji HJ, Zhi Y, Kang BS, Bahn YS, Seo HS, Lim S (2020) Antioxidant activities of an exopolysaccharide (DeinoPol) produced by the extreme radiation-resistant bacterium Deinococcus radiodurans. Nat Sci Rep 63(10):55

27. Yasuda T, Inaba A, Ohmori M, Endo T (2000) Urinary metabolites of gallic acid in rats and their radical scavenging effect on DPPH. J Nat Prod 63: 1444-1446

28. Cheng BH, Chan JYW, Chan BCL (2014) Structural characterization and immunomodulatory effect of a polysaccharide HCP-2 from Houttuynia cordata. Carbohydr Polym 103:244-249

29. Venkateswarulu TC, Kodali VP, Kumar RB (2017) Optimization of nutritional components of medium by response surface methodology for enhanced production of lactase. 3 Biotech 7(3):202

30. Soares JR, Dins TCP, Cunha AP, Ameida LM (1997) Antioxidant activity of some extracts of Thymus zygis. Free Radic Res 26:469-478

31. Haschemie KK, Renger A, Steinhart H (1996) A comparison between reductive-cleavage and standard methylation analysis for determining structural features of galactomannans. Carbohydr Polym 30(1):31-35

32. Knight $J$ (1998) Free radicals: their history and current status in aging and disease. Ann Clin Lab Sci 28:331-346

33. Sun T, Powers JR, Tang J (2007) Evaluation of the antioxidant activity of asparagus, broccoli and their juices. Food Chem 105:101-106

34. Kodali VP, Das S, Sen R (2009) An exopolysaccharide from a probiotic: biosynthesis dynamics, composition and emulsifying activity. Food Res Int 42:695-699

35. Venkateswarulu TC, Prabhakar KV, Kumar RB, Krupanidhi S (2017) Modeling and optimization of fermentation variables for enhanced production of lactase by isolated Bacillus subtilis strain VUVD001 using artificial neural networking and response surface methodology. 3 Biotech 7(3):1-9

\section{Publisher's Note}

Springer Nature remains neutral with regard to jurisdictional claims in published maps and institutional affiliations.

\section{Submit your manuscript to a SpringerOpen ${ }^{\circ}$ journal and benefit from:}

- Convenient online submission

- Rigorous peer review

- Open access: articles freely available online

High visibility within the field

- Retaining the copyright to your article

Submit your next manuscript at $>$ springeropen.com 